\title{
Evaluation of a Pomegranate Peel Extract as an Alternative Means to Control Olive Anthracnose
}

\author{
Sonia Pangallo, Maria G. Li Destri Nicosia, Giovanni E. Agosteo, Ahmed Abdelfattah, Flora V. Romeo, Santa O. Cacciola, \\ Paolo Rapisarda, and Leonardo Schena ${ }^{\dagger}$
}

First, second, third, fourth, and eighth authors: Dipartimento di Agraria, Università Mediterranea di Reggio Calabria, Località Feo di Vito, Reggio Calabria 89122, Italy; fifth and seventh authors: Consiglio per la ricerca in agricoltura e l'analisi dell'economia agraria (CREA)-Centro di Ricerca Olivicoltura, Frutticoltura e Agrumicoltura (CREA-OFA), Corso Savoia 190, 95024 Acireale (CT) 95024; and sixth author: Dipartimento di Agricoltura, Alimentazione e Ambiente, Università degli Studi, Via S. Sofia 100, 95123 Catania, Italy. Accepted for publication 28 July 2017.

\begin{abstract}
Olive anthracnose is caused by different species of Colletotrichum spp. and may be regarded as the most damaging disease of olive fruit worldwide, greatly affecting quality and quantity of the productions. A pomegranate peel extract (PGE) proved very effective in controlling the disease. The extract had a strong in vitro fungicidal activity against Colletotrichum acutatum sensu stricto, was very effective in both preventive and curative trials with artificially inoculated fruit, and induced resistance in treated olive tissues. In field trials, PGE was significantly more effective than copper, which is traditionally used to control the disease. The highest level of protection was achieved by applying the extract in the early ascending phase of the disease outbreaks because

natural rots were completely inhibited with PGE at $12 \mathrm{~g} / \mathrm{liter}$ and were reduced by 98.6 and by $93.0 \%$ on plants treated with PGE at 6 and $3 \mathrm{~g} / \mathrm{liter}$, respectively. Two treatments carried out 30 and 15 days before the expected epidemic outbreak reduced the incidence of the disease by 77.6, 57.0, and $51.8 \%$, depending on the PGE concentration. The analysis of epiphytic populations showed a strong antimicrobial activity of PGE, which sharply reduced both fungal and bacterial populations. Because PGE was obtained from a natural matrix using safe chemicals and did not have any apparent phytotoxic effect on treated olive fruit, it may be regarded as a safe and effective natural antifungal preparation to control olive anthracnose and improve olive productions.
\end{abstract}

Olive anthracnose, caused by different species of Colletotrichum, is the most important disease of olive fruit worldwide, resulting in heavy economic losses (Cacciola et al. 2012; Moral et al. 2014). Affected olive drupes show dark necrosis followed by fruit rot and mummification. Under moist conditions, abundant orange conidial masses are produced on the surface of infected drupes whereas, under dry conditions, the fruit mummify and lose weight due to dehydration. Infected fruit fall prematurely to the ground and only a few mummies remain attached to the tree. The disease is commonly severe on mature fruit but green drupes of susceptible cultivars also can be infected under favorable conditions. The quality of oil from infected drupes is highly compromised due to a reddish color, high acidity, and a major reduction of polyphenols, $\alpha$-tocopherol, and $\beta$-sitosterol (Moral et al. 2014). Colletotrichum spp. can also infect other olive organs, including leaves, fruit pedicels, and flowers, but the economic relevance of these infections is considered of secondary importance (Cacciola et al. 2012).

According to recent taxonomic rearrangements, olive anthracnose is caused by a fungal complex consisting of Colletotrichum acutatum sensu lato and C. gloeosporioides sensu lato (Damm et al. 2012; Weir et al. 2012). Furthermore, C. karstii, a species belonging to the $C$. boninense complex, has also been associated with the disease (Schena et al. 2014). C. gloeosporioides sensu lato species have been rarely associated with epidemic outbreaks, though some species of this complex have shown a high level of virulence on artificially inoculated fruit (Schena et al. 2014). In any case, the most economically relevant species belong to the $C$. acutatum sensu lato complex. Among these, C. godetiae (syn. C. clavatum) has been traditionally considered the most prevalent olive anthracnose pathogen

${ }^{\dagger}$ Corresponding author: L. Schena; E-mail: 1schena@unirc.it

(C) 2017 The American Phytopathological Society in Italy and other central Mediterranean countries (Cacciola et al. 2012; Faedda et al. 2011; Talhinhas et al. 2015). In Spain, C. simmondsii is the dominant species in Catalonia whereas $C$. godetiae seems to be prevalent in Andalusia (Moral et al. 2014). In Portugal, the prevalent species is $C$. nymphaeae, followed by $C$. simmondsii and $C$. godetiae (Talhinhas et al. 2011). Another important species, C. acutatum sensu stricto, until a few years ago had been reported only in the region of the Algarve in Portugal, and seemed to be the prevalent species on olive in Australia and South Africa (Talhinhas et al. 2011). However, recent investigations have also revealed a wide diffusion of this species in southern Italy and in northern Tunisia (Chattaoui et al. 2016; Mosca et al. 2014). In Calabria, southern Italy, there is evidence to indicate an ongoing process of population shift from $C$. godetiae to C. acutatum sensu stricto, which is now the most important causal agent of olive anthracnose (Abdelfattah et al. 2015; Mosca et al. 2014; Schena et al. 2017).

The management of olive anthracnose and other fruit rot is generally based on Integrated Pest Management approaches, which include chemical treatments, selection of resistant cultivars, and early harvesting in order to escape secondary infections (Cacciola et al. 2012). Control of the olive fruit fly attacks may also be useful to reduce the disease because the fly may act as vector and facilitate infection through oviposition wounds (Malacrinò et al. 2015, 2017). In olive-growing areas where anthracnose is endemic, frequent rains in the fall and high humidity may reduce the persistence of fungicide treatments. Therefore, several fungicide treatments are needed to control the disease. Furthermore, the need to avoid fungicide residues in olive oil and to comply with the regulation on preharvest fungicide intervals can leave the drupes unprotected in a developmental stage of very high susceptibility and in a season when environmental conditions are conducive to the disease. In Calabria, two to three preventive treatments with copper formulates from late September to the end of December are considered quite effective against the disease, whereas high-humidity conditions can 
significantly reduce the efficacy of treatments (Agosteo et al. 2007; Graniti et al. 1993; Pennisi et al. 1993). In Australia, copper-based fungicides and strobilurins applied under field conditions failed to control anthracnose disease regardless of the timing of application (Sergeeva 2011). Spring treatments commonly carried out to control peacock spot caused by Spilocea oleagina may also help reduce blossom blight and reduce latent infections, which represent an important inoculum source for fall infections (Moral et al. 2014). Recently, two commercial formulates containing trifloxystrobin + tebuconazol and pyraclostrobin have been registered in Italy on olive only for application during spring and early summer, respectively.

Restrictions in the use of copper fungicides due to the toxicity of $\mathrm{Cu}^{2+}$ ions and their adverse effects in soil and water have prompted research into substances that may substitute its use. In this context, the role of olive oil as a major component of the Mediterranean diet is urging effective alternative control means to ensure high-quality productions and the absence of chemical residues. In Calabria, field trials on 'Cassanese' (moderately susceptible) and 'Ottobratica' (highly susceptible) olive with sodium bicarbonate $\left(\mathrm{NaHCO}_{3}\right)$ significantly reduced the proportion of drupes affected by anthracnose, even though the efficacy of treatments depended on the susceptibility of the cultivars (Agosteo et al. 2007). Recently, several fungi isolated from olive proved to inhibit the growth of C. acutatum; however, only in vitro tests were performed (Landum et al. 2016). In another study, nutrients and microorganisms from the olive carposphere were found to play an important role in the infection processes of C. godetiae (Agosteo et al. 2015).

In recent years, particular interest has been shown in plant extracts (i.e., biodegradable substances with low toxicity to the environment) that exhibit a direct fungicidal or fungistatic activity and can also induce resistance in treated plant hosts (Chen and Dai 2012; Palou et al. 2016). Typically, bioactive compounds contained in plant extracts are products of secondary metabolism produced by the plant for its own protection against pests and pathogens. They have been used in a number of host-pathogen combinations and some have proved very effective, suggesting the possible development of natural antifungal compounds that would be as effective as synthetic fungicides (Schena et al. 2007). Among others, an alcoholic extract obtained from the peel of pomegranate (pomegranate peel extract [PGE]) seems to be promising for the development of alternative control strategies against fungal plant pathogens. It has shown a high efficacy against several postharvest diseases caused by major necrotrophic fungi, including Botrytis cinerea on table grape and sweet cherry, Monilinia laxa on sweet cherry, Penicillium digitatum and $P$. italicum on lemon and grapefruit, and P. expansum on apple (Li Destri Nicosia et al. 2016; Romeo et al. 2015). Currently, the available data indicate the possible implementation of PGE to control plant diseases in different host-pathogen combinations because it showed a broad spectrum of activity, strong direct antimicrobial effects, and both curative and preventive activities with long persistence, even when applied under semicommercial conditions (Li Destri Nicosia et al. 2016). Furthermore, recent investigations have demonstrated the elicitation of resistance responses in grapefruit and lemon fruit treated with PGE (Pangallo et al. 2017).

The aim of the present work was to evaluate the efficacy of PGE as an alternative control method against olive anthracnose. Experiments were conducted in vitro, on artificially inoculated fruit, and under field conditions to determine the efficacy, the mechanisms of action, and the reliability of PGE as a safe and effective means of control.

\section{MATERIALS AND METHODS}

Pomegranate extract and inoculum preparation. A concentrated PGE was obtained according to Romeo et al. (2015) from organic ripe 'Wonderful' pomegranate (Punica granatum L.) fruit, harvested in Acireale (Italy). The concentrated solution, containing dry matter at $120 \mathrm{~g} /$ liter and $1 \%$ citric acid as antioxidant, was stored at $5^{\circ} \mathrm{C}$ until use.

A fungal isolate of $C$. acutatum sensu stricto was obtained from a rotted olive fruit collected in Calabria, southern Italy. A conidial suspension of the pathogen was serially diluted with sterile water and plated on potato dextrose agar (PDA) (Sigma-Aldrich) in order to obtain cultures from single conidia. The identity of $C$. acutatum sensu stricto was confirmed according to morphological features and by sequencing the internal transcribed spacer (ITS) 1-5.8S-ITS2 region and the $\beta$-tubulin 2 gene, as described by Schena et al. (2014).

To produce the inoculum, $C$. acutatum sensu stricto was grown on PDA for 10 days and conidia were collected with a spatula, suspended in sterile distilled water, filtered through a double layer of sterile muslin cloth (Artsana), and uniformly mixed. The concentration of the conidia in the suspension was determined using a hemocytometer chamber (Brand $\mathrm{GmbH}$ ) and diluted to have stock solutions containing $10^{5}$ conidia/ml.

In vitro antifungal activity of PGE. The effect of PGE on spore germination and germ tube elongation of $C$. acutatum sensu stricto was determined using the procedure recently described by $\mathrm{Li}$ Destri Nicosia et al. (2016). Briefly, a conidial suspension of the pathogen was transferred into Eppendorf tubes containing potato dextrose broth (PDB) and PGE at three different concentrations $(0.12$, 1.2 , and $12 \mathrm{~g} /$ liter) and incubated at $22^{\circ} \mathrm{C}$ for $20 \mathrm{~h}$. Water replaced the PGE solution in control samples. Three groups of 50 spores each were randomly selected and examined under a microscope to determine the percentage of germinated conidia and the average length of the germ tubes. Conidia were considered germinated when the length of the germ tube was at least equal to the diameter of the nongerminated conidia.

Antifungal activity of PGE on detached fruit. All the trials were performed on healthy detached 'Leccino' olive fruit collected in the Monopoli area, southern Italy, where local climatic conditions are generally not conducive for olive anthracnose. Drupes, selected for uniformity in size and color and for the absence of olive fruit fly damage, were surface disinfected by immersion in a $2 \%$ sodium hypochlorite solution for $1 \mathrm{~min}$, rinsed with tap water, air dried, and fixed on polypropylene honeycomb panels, as previously described (Li Destri Nicosia et al. 2016). All experiments were performed using three replicates of 10 fruit each, with each replicate kept in separate plastic boxes. In all the experiments, fruit were kept 0.5 to $1 \mathrm{~cm}$ apart to avoid nesting and wounded with a nail to make 1-by-1-mm injuries. Wounds were treated with $10 \mu \mathrm{l}$ of PGE at a concentration of $12,1.2$, or $0.12 \mathrm{~g} /$ liter and inoculated with $10 \mu \mathrm{l}$ of a spore suspension of $C$. acutatum sensu stricto. Mock wounds, treated with $1 \%$ citric acid or sterile water and inoculated with the pathogen, served as controls.

To evaluate the preventive effect, wounds were treated with the PGE and incubated for 1,12 , or $24 \mathrm{~h}$ before inoculation with the pathogen whereas, to determine the curative effect, drupes were first inoculated with the pathogen and then treated with PGE after 6, 12, or $24 \mathrm{~h}$. Finally, to evaluate the induction of resistance in the host tissues, PGE and pathogen were applied at two different sites approximately $7 \mathrm{~mm}$ apart on each olive fruit. Drupes were first treated with PGE and then inoculated with the pathogen after 6,12 , or $24 \mathrm{~h}$.

All experiments were repeated twice and olive fruit were maintained at $20^{\circ} \mathrm{C}$ in lidded plastic boxes containing wet paper to ensure high relative humidity. The percentage of infected wounds was evaluated daily starting 4 days postinoculation.

Field trials on naturally infected olive fruit. Field trials were carried out in 2015 and 2016 in intensive olive orchards located in the Gioia Tauro and Oppido Momertina areas of Calabria, southern Italy, which are very close together. In 2015, treatments were applied to 'Arbosana' olive and the experiment was planned soon after the appearance of the first rotted olive fruit (November 10). The incidence of the disease at the time that treatments were applied was approximately $5 \%$ of the pending olive fruit. Before 
treatments, plants were shaken vigorously to bring down all the rotted olive fruit. In 2016, two different treatments were applied to Ottobratica olive approximately 30 and 15 days (13 and 28 October, respectively) before the expected epidemic outbreak of the disease.

In both years, plants (three per treatment) were selected within a randomized block design to be uniform in terms of tree size of and quantity of pending production. Treatments included PGE at three different concentrations (12, 6, and $3 \mathrm{~g} / \mathrm{liter}$ ), copper (Bordeaux

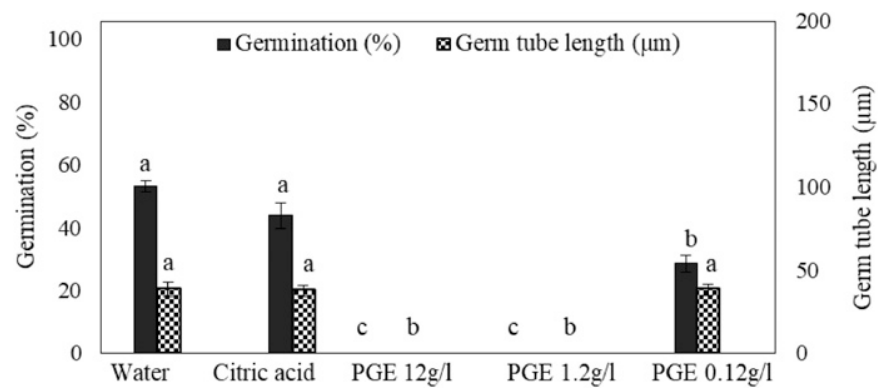

Fig. 1. Effect of pomegranate peel extract (PGE) on germination and germ tube elongation of conidia of Colletotrichum acutatum sensu stricto incubated for $20 \mathrm{~h}$ at $22^{\circ} \mathrm{C}$ in potato dextrose broth (PDB) containing PGE at different concentrations $(12,1.2$, or $0.12 \mathrm{~g} /$ liter). Conidia incubated in PDB containing water and $1 \%$ citric acid served as a control. Bars indicate standard errors of the means. For both investigated parameters (germination and germ tube length), different letters indicate significantly different values according to Tukey's test $(P \leq 0.05)$.

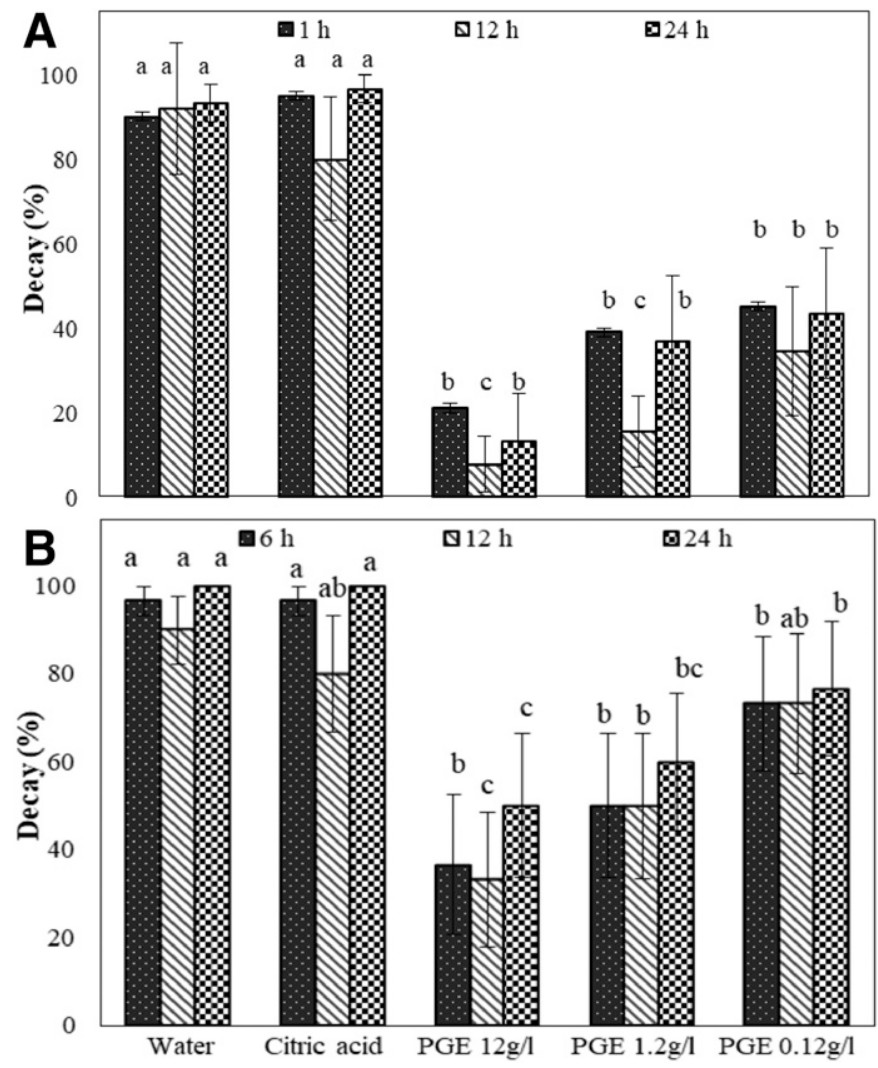

Fig. 2. A, Preventive and B, curative effect of pomegranate peel extract (PGE) on artificially inoculated olive fruit. In preventive trials, fruit were first treated with PGE and then inoculated with a spore suspension of Colletotrichum acutatum sensu stricto after 1,12 , or $24 \mathrm{~h}$. In curative trials, olive fruit were first inoculated with a spore suspension of the pathogen and then treated with PGE after 6,12 , and $24 \mathrm{~h}$. In both trials, PGE was tested at different concentrations $(12,1.2$, or $0.12 \mathrm{~g} /$ liter) and fruit mock treated with water or $1 \%$ citric acid and inoculated with the pathogen served as controls. Bars indicate standard errors of the means. For each assessment time, different letters indicate significantly different values according to Tukey's test $(P \leq 0.05)$. mixture 20 GD Caffaro, $\left.20 \% \mathrm{Cu}^{++}\right)$, and $\mathrm{NaHCO}_{3}(2 \%$ [wt/vol]; Sigma-Aldrich). Three olive trees treated with tap water and three untreated trees were used as controls. All the treatments were applied using a commercial electric-driven back sprayer (Mod. Serena; Italdifra) and each tree received approximately 3 liters of solution or water.

The incidence of the disease expressed as percentage of infected olive fruit was determined 3 and 7 days after the treatment in 2015 and 30 days after the first treatment in 2016. In both years, 100 olive fruit were randomly collected from each tree (300 olive fruit per treatment) and accurately observed for the presence of anthracnose symptoms. Leaves and fruit were also examined to exclude the presence of any symptoms of phytotoxicity.

Effects of treatments on epiphytic fungal and bacterial populations. The effects of treatments on fungal and bacterial populations on olive drupes was evaluated in 2015 on treated and untreated olive fruit 2 days after field treatments. Three replications of 10 apparently healthy fruit were randomly picked from each olive tree to comprise 90 olive fruit per thesis. Collected drupes were shaken in $100 \mathrm{ml}$ of sterile distilled water on a rotatory shaker at $150 \mathrm{rpm}$ for $30 \mathrm{~min}$. Rinse water $(100 \mu \mathrm{l})$ was serially diluted and plated on PDA containing ampicillin and streptomycin sulfate ( $250 \mathrm{mg} / \mathrm{liter})$ to determine fungal colonies and PDA without antibiotics to detect bacteria. The plates (three per replication) were incubated at $22^{\circ} \mathrm{C}$ for 3 to 4 days. The number of fungal and bacterial colonies (CFU) was recorded and converted into CFU fruit ${ }^{-1}$.

Statistical analyses. In all the trials, data were submitted to the analysis of variance (ANOVA) and means were compared using Tukey's test $(P<0.05)$ to determine the significance of the treatments. In the curative essay on detached olive, a two-factor essay (general linear model) was performed in order to determine the effect of treatment and timing and their interactions on the rot development. Percentages were converted into Bliss angular values (arcsine $\sqrt{ } \%$ ) before analysis.

\section{RESULTS}

In vitro antifungal activity of PGE. The germination of conidia of $C$. acutatum sensu stricto was completely inhibited in PDB containing PGE at 12 and 1.2 g/liter (Fig. 1). Furthermore, a significant reduction of the germination $(46.3 \%)$ was also achieved with PGE at $0.12 \mathrm{~g} /$ liter, although the length of germ tubes with this concentration of extract was not significantly different compared with the controls (water and citric acid).

The citric acid had an inconsistent inhibiting effect on the germination of the conidia and did not affect the length of the germ tubes (Fig. 1).

Efficacy of PGE on artificially inoculated olive fruit. Preventive effect. PGE significantly reduced the incidence of rot caused by $C$. acutatum sensu stricto at all tested concentrations when applied 1, 12, and $24 \mathrm{~h}$ before inoculation with the pathogen (Fig. 2A). In particular, PGE at 12, 1.2, and $0.12 \mathrm{~g} /$ liter applied $1 \mathrm{~h}$ before the pathogen reduced percentage of rotting by 76.7, 56.7, and $50 \%$, respectively. The same extract concentrations applied 12 and $24 \mathrm{~h}$ before the pathogen reduced the incidence of rot by $91.7,83.3$, and $62.5 \%$ and by $85.7,60.7$, and $53.5 \%$, respectively (Fig. 2). Citric acid did not significantly affect the incidence of rot.

Curative effect. PGE at 12 and $1.2 \mathrm{~g} /$ liter significantly reduced the incidence of decay when applied 6,12, and $24 \mathrm{~h}$ after the pathogen (Fig. 2B). At the lowest tested concentration (0.12 g/liter), significant reductions were achieved at 6 and 24 but not $12 \mathrm{~h}$. Rots were reduced by $62.2,48.2$, and $24.1 \%$ at $6 \mathrm{~h}$; by $63.0,44.4$, and $18.5 \%$ at $12 \mathrm{~h}$; and by $50.0,40.0$, and $23.5 \%$ at $24 \mathrm{~h}$ using PGE at $12,1.2$, and $0.12 \mathrm{~g} / \mathrm{liter}$, respectively. Overall, the highest level of protection was achieved with PGE at $12 \mathrm{~g} /$ liter, followed by PGE at 1.2 and $0.12 \mathrm{~g} /$ liter, although differences were not statistically significant in most of the cases (Fig. 2B). Citric acid did not significantly affect the incidence of rot. 
The ANOVA two-factor essay confirmed that the development of rot was significantly affected by the PGE treatment $(F=63.41$, $\mathrm{df}=4, P<0.001)$ and by the timing of application $(F=10.16$, $\mathrm{df}=2$, $P<0.001)$ but excluded any significant time-treatment interaction $(F=1.59$, df $=8, P=0.168)$.

Induction of resistance. A significant reduction of rot was achieved with PGE at 12 and $24 \mathrm{~g} /$ liter without direct contact between the pathogen and PGE, suggesting the induction of resistance in olive fruit treated with the extract (Fig. 3). In particular, PGE at $12 \mathrm{~g} / \mathrm{liter}$ reduced rots by $53.5,59.3$, and $40.7 \%$ in olive fruit inoculated with the pathogen 6,12 , and $24 \mathrm{~h}$ after the extract, respectively. At the same inoculation times, PGE at $1.2 \mathrm{~g} /$ liter reduced rots by $46.4,37.0$, and $33.3 \%$, respectively. Furthermore, a significant reduction was achieved with PGE at the lowest concentration $(0.12 \mathrm{~g} /$ liter $)$ at $24 \mathrm{~h}$ $(P \leq 0.05)$.

Field trials on naturally infected olive fruit. In 2015, the incidence of natural rot on olive trees sharply increased after 10 November (treatment date) and reached $100 \%$ of the drupes after just 3 days on untreated and water-sprayed plants (Fig. 4). In contrast, the development of natural rot was completely inhibited on olive trees treated with PGE at $12 \mathrm{~g} /$ liter and was reduced by 98.6 and $93.0 \%$ on plants treated with PGE at 6 and $3 \mathrm{~g} /$ liter, respectively (Fig. 4). PGE was significantly more effective than copper and $\mathrm{NaHCO}_{3}$ at all tested concentrations $(P \leq 0.05)$. In particular, 3 days after treatments, the incidence of infected drupes on plants treated with copper and $\mathrm{NaHCO}_{3}$ was significantly reduced by 58.8 and $55.0 \%$, respectively. No significant differences were revealed between $\mathrm{NaHCO}_{3}$ and copper (Fig. 4). Seven days after the treatment, PGE at 12, 6, and $3 \mathrm{~g} /$ liter still reduced the incidence of rotted olive fruit compared with the controls by $84.4,73.0$, and $72.2 \%$, respectively. A significant reduction was also revealed for $\mathrm{NaHCO}_{3}$ and copper but the entity of the reduction (around 27\%) was much lower compared with PGE treatments (Fig. 4).

Trials conducted in 2016 confirmed a high efficacy of PGE, which significantly reduced rot at all concentrations. However, a lower level of protection was generally observed compared with 2015. In particular, rot was reduced by 77.6, 57.0, and $51.8 \%$ using PGE at 12, 6, and $3 \mathrm{~g} /$ liter; and by 46.5 and $36 \%$ with copper and $\mathrm{NaHCO}_{3}$, respectively (Fig. 5). PGE at 12 g/liter was significantly more effective than copper and $\mathrm{NaHCO}_{3}$. Notably, no signs of phytotoxicity were detected on the plants in either of the trials.

Effects of treatments on fungal and bacterial populations. PGE treatments significantly reduced fungal and bacterial populations at all tested concentrations (Fig. 6). In particular, fungal populations were reduced by $99.5,83.9$, and $75.9 \%$ using PGE at 12,6 , and 3 g/liter; and by 68.3 and $52.5 \%$ using copper and $\mathrm{NaHCO}_{3}$, respectively (Fig. 6A). A slightly higher level of population was revealed on olive fruit sprayed with water when compared with untreated olive fruit but differences were not significant $(P \leq 0.05)$.

A similar trend was determined for bacteria (Fig. 6B). Their population was reduced by $98.2,91.4$, and $85.2 \%$ on olive fruit treated with PGE at 12, 6, and $3 \mathrm{~g} / \mathrm{liter}$; and by 78.7 and $55 \%$ on those treated with copper and $\mathrm{NaHCO}_{3}$, respectively. Significant differences were observed between $\mathrm{NaHCO}_{3}$ - and PGE-treated drupes. As for fungi, a slightly higher level of population was revealed on olive fruit sprayed with water compared with untreated olive fruit but the differences were not significant $(P \leq 0.05)$.

\section{DISCUSSION}

In the present study, we demonstrated the feasibility of PGE as a very effective natural antifungal preparation to control olive anthracnose caused by Colletotrichum spp. Preliminary in vitro tests and experiments conducted on artificially inoculated drupes highlighted a strong antimicrobial activity and a high efficacy of PGE in preventive and curative applications. Similar results were obtained in previous investigations focused on important necrotrophic pathogens such as B. cinerea, $P$. digitatum, $P$. italicum, and $P$. expansum
(Li Destri Nicosia et al. 2016; Romeo et al. 2015). The high efficacy of PGE also against typical hemibiotrophic fungi such as $C$. acutatum spp. (Guidarelli et al. 2011) is further proof of its broad spectrum of activity, which may contribute toward making economically sustainable the costly process needed for the registration and commercialization of natural products.

On drupes artificially inoculated with $C$. acutatum sensu stricto, a significant reduction of rot was also achieved without direct contact between PGE and the pathogen, suggesting a strong induction of resistance, enough to inhibit the pathogen development and the infection of the drupes. Previous investigations demonstrated that PGE can increase the activity of reactive oxygen species and activate genes involved in defense responses such as chitinase, chalcone synthase, mitogen-activated protein kinase, mitogen-activated protein kinase kinase, and phenylalanine ammonia lyase in grapefruit (Pangallo et al. 2017). Although the molecular nature of the induced resistance in olive fruit was not investigated, our results support a nonhost-specific induction, confirming previous speculations on the broad range of application of PGE.

The induction of resistance may have also played a role in the high efficacy observed when PGE was applied 12 or $24 \mathrm{~h}$ before the pathogen. The ability of PGE to protect olive fruit for several hours

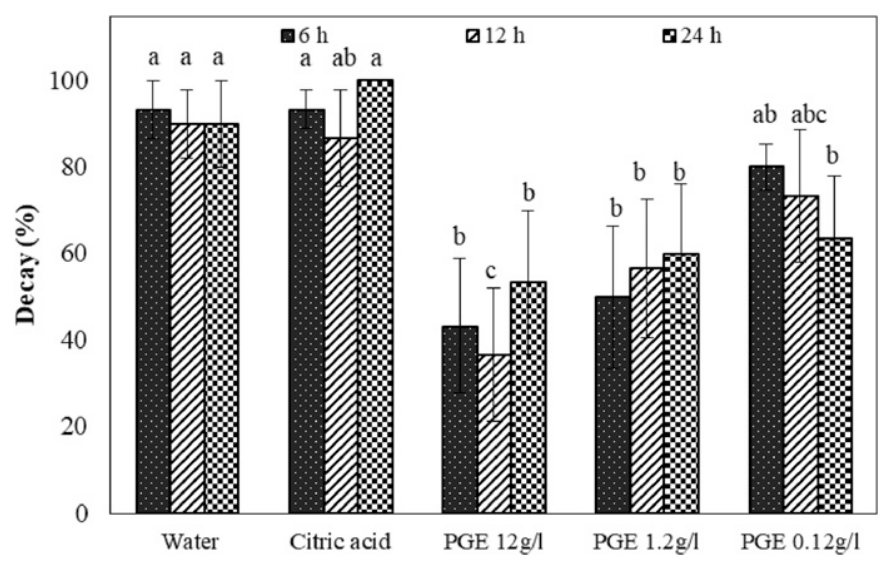

Fig. 3. Incidence of decay in olive fruit treated with pomegranate peel extract (PGE) and inoculated with Colletotrichum acutatum sensu stricto in spatially separated wounds (induction of resistance). PGE was applied 6, 12, or $24 \mathrm{~h}$ before the pathogen at different concentrations $(12,1.2$, or $0.12 \mathrm{~g} / \mathrm{liter})$. Fruit mock treated with water or $1 \%$ citric acid and inoculated with the pathogen served as controls. Bars indicate standard errors of the means. For each assessment time, different letters indicate significantly different values according to Tukey's test $(P \leq 0.05)$.

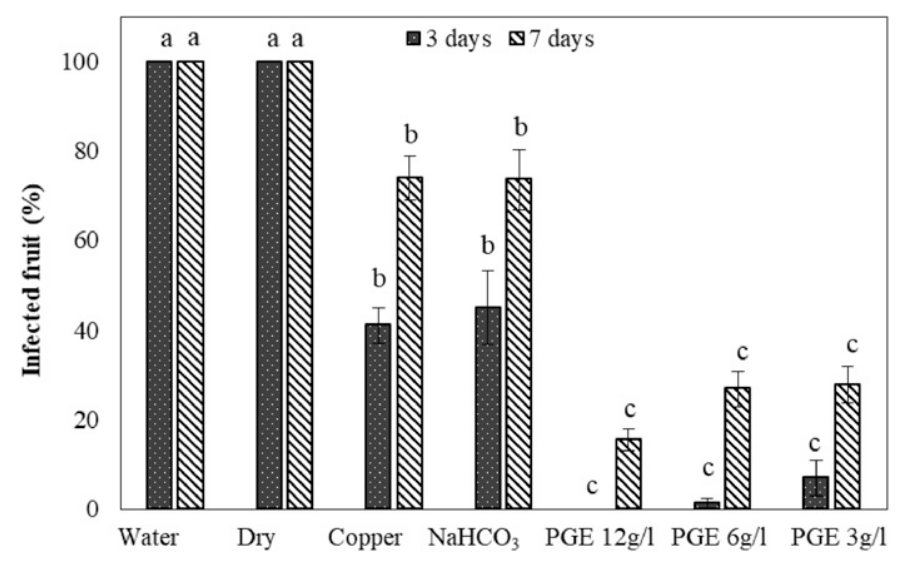

Fig. 4. Incidence of rotted drupes on Arbosana olive trees treated in 2015 with pomegranate peel extract (PGE) at three different concentrations, copper, or $\mathrm{NaHCO}_{3}$. Olive trees untreated or sprayed with tap water were used as controls. The incidence of rotted olive fruit was evaluated 3 and 7 days after treatments. Bars indicate standard errors of the means. For each assessment time, different letters indicate significantly different values according to Tukey's test $(P \leq 0.05)$. 
after its application is a very important feature and may prove synergic with the observed curative activity. Indeed, PGE also significantly reduced the incidence of rot on fruit treated 6,12 , and $24 \mathrm{~h}$ after the pathogen inoculation (i.e., sufficient time for conidia to germinate and start the infection process). It has been reported that latent infections established during early fruit development phases play an important role in the disease cycle of olive anthracnose by favoring the survival of the pathogen during the summer period and represent an important source of inoculum for epidemics on ripening fruit (Moral et al. 2014; Talhinhas et al. 2011). In this context, a natural compound able to reduce latent infections and protect fruit after its application may be extremely useful.

The results obtained in field trials by simulating practical commercial conditions were particularly remarkable. Indeed, although many alternative control methods have proved effective under

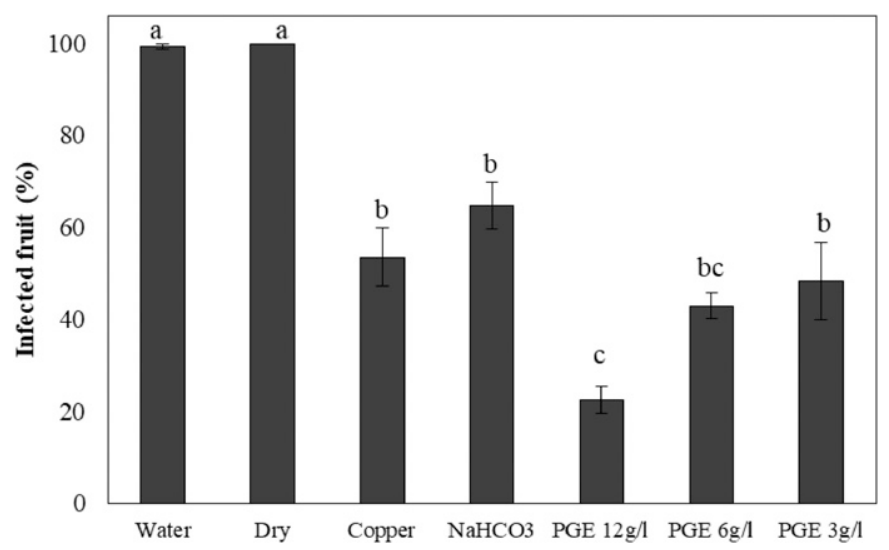

Fig. 5. Incidence of rotted drupes on Ottobratica olive trees treated in 2016 with pomegranate peel extract (PGE) at three different concentrations, copper, or $\mathrm{NaHCO}_{3}$. Olive trees untreated or sprayed with tap water were used as controls. Treatments were made 15 and 30 days before the evaluation of the incidence of the disease. Bars indicate standard errors of the means. Different letters indicate significantly different values according to Tukey's test $(P \leq 0.05)$.
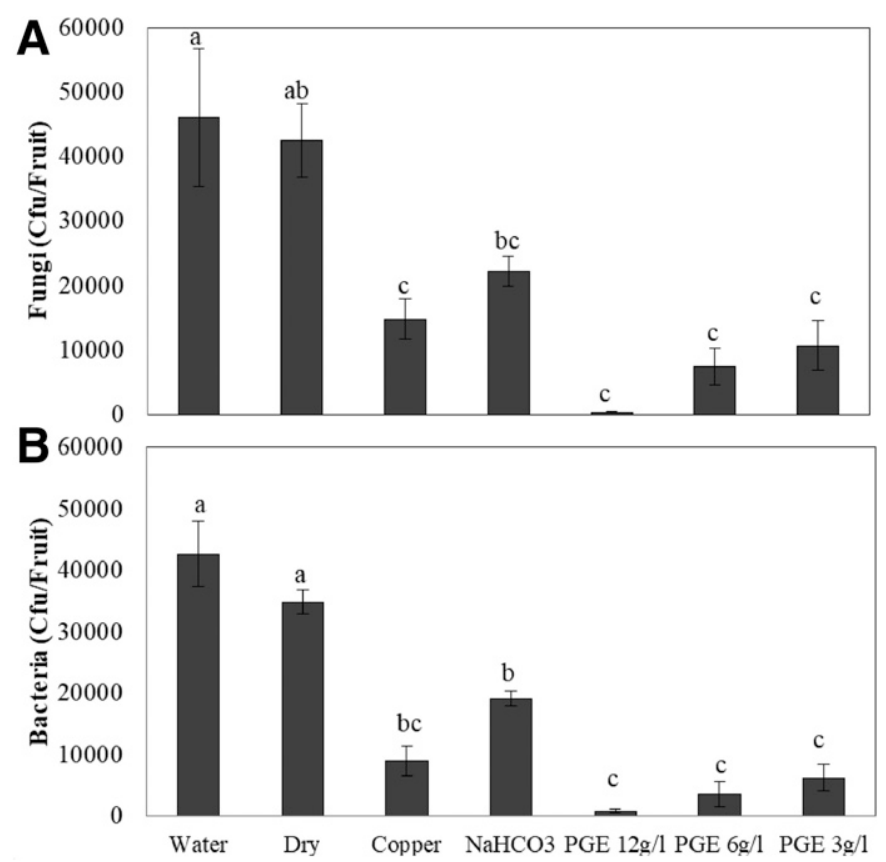

Fig. 6. Composition of A, fungal and B, bacterial populations on Arbosana olive drupes treated in 2015 with pomegranate peel extract (PGE) at three different concentrations, copper, or $\mathrm{NaHCO}_{3}$. Drupes untreated or sprayed with tap water were used as controls. Bars indicate standard errors of the means. Different letters indicate significantly different values according to Tukey's test $(P \leq 0.05)$. laboratory conditions, most of them failed when tested in largescale trials. The highest level of protection was achieved in 2015, when PGE was applied soon after the appearance of the first rotted olive fruit (i.e., at the early ascending phase of the disease outbreaks). After 3 days, the incidence of the disease on control plants (untreated or sprayed with water) reached $100 \%$, whereas natural rot was completely inhibited on olive trees sprayed with PGE at $12 \mathrm{~g} /$ liter and was reduced by 98.6 and by $93.0 \%$ on plants treated with PGE at 6 and $3 \mathrm{~g} / \mathrm{liter}$, respectively. The high incidence of the disease on control plants after only 3 days suggests that most olive fruit may have already been infected, although still asymptomatic, when treated with the extract. These results, in agreement with the above-discussed tests on artificially inoculated drupes, indicate a strong curative action of PGE. On the other hand, the existence of ongoing infections at the treatment time may explain the low efficacy of copper, which is a typical protective chemical. Interestingly, a very high level of protection was achieved on PGE-treated olive fruit, even 7 days after treatments, confirming a long-term protection of the treated olive fruit, with very important practical implications.

A high level of efficacy against olive anthracnose was also achieved in 2016 using a different application strategy because two anticipated treatments were carried out approximately 30 and 15 days before the expected epidemic outbreak of the disease. Compared with 2015, PGE provided a lower level of protection (ranging from 77.6 and $51.8 \%$, according to the concentration) yet it was significantly more effective than copper and $\mathrm{NaHCO}_{3}$. These results may suggest that the most successful strategy is the application of PGE at the early ascending phase of disease outbreaks. However, more investigations are needed to define dosage, time, and method of application in consideration of the many factors that can affect the efficacy of treatments under field conditions. For instance, in 2016, recurrent heavy rains created very conducive conditions for the disease and prevented the access to the field during the early phases of the epidemic outbreak when differences between treated and untreated trees were likely to be higher. Nevertheless, it is important to highlight that both field trials were conducted under very conducive conditions due to the high sensitivity of the investigated olive cultivars (Arbosana and Ottobratica) and the prolonged wet periods typical of the investigated area (Cacciola et al. 2012).

Overall, our results demonstrate a very high potentiality of PGE in controlling olive anthracnose because it provided very high levels of protection and was significantly more effective than copper, which is traditionally used to control the disease (Cacciola et al. 2012). Furthermore, copper has serious ecological drawbacks because its use can lead to pollution of aquifers and to an accumulation in the soil, with toxic effects for both the microbial population and the fauna of the land and crops. It is also of concern that it may have harmful effects on human health (Cacciola et al. 2012). In field trials, we also used $\mathrm{NaHCO}_{3}$, which has been reported as an alternative control mean for olive anthracnose (Agosteo et al. 2007). Although $\mathrm{NaHCO}_{3}$ was the least effective treatment, it still provided a significant reduction of rot. This salt may be useful in integrated control strategies in consideration of its safety and low costs as well as the lack of legislative restrictions that allows its distribution before harvesting (Nigro et al. 2006).

The analysis of epiphytic populations on olive drupes highlighted a strong and broad antimicrobial activity of PGE, which significantly reduced both fungal and bacterial populations. The high content of punicalagins in PGE (Romeo et al. 2015) is likely to play a role in this activity because these phenolic compounds, characteristic of pomegranate, are well known for their antimicrobial activity (Glazer et al. 2012; Taguri et al. 2004). These results suggest the need for specific studies to evaluate the degradation rate of PGE and its long-term impact on natural microbial populations. Furthermore, its toxicity for humans and other mammals needs to be evaluated. However, the fact that pomegranate peel extracts are commonly used as food additives, functional food ingredients, or biologically 
active components in nutraceutical preparations is more than encouraging (Akhtar et al. 2015). Furthermore, the medicinal properties of pomegranate peel tannins have been traditionally used to treat several common ailments and prevent bone loss (Spilmont et al. 2015). In this context, it is also important to highlight that PGE is obtained using safe, food-grade chemicals such as ethanol and citric acid (Romeo et al. 2015) and, in the present study as well as in previous investigations, did not show any phytotoxic effects (Li Destri Nicosia et al. 2016).

\section{ACKNOWLEDGMENTS}

This research was funded by The Italian Ministry of Education, University and Research with grant "Modelli sostenibili e nuove tecnologie per la valorizzazione delle olive e dell'olio extravergine di oliva prodotto in Calabria - PON Ricerca e competitività 2007-2013 (PON03PE_00090_02). We thank A. Davies for the revision of the English text.

\section{LITERATURE CITED}

Abdelfattah, A., Nicosia, M. G. L. D., Cacciola, S. O., Droby, S., and Schena, L. 2015. Metabarcoding analysis of fungal diversity in the phyllosphere and carposphere of olive (Olea europaea). PLoS One 10:e0131069.

Agosteo, G. E., Sanzani, S. M., Carmela, M., Cacciola, S. O., Li Destri Nicosia, M. G., and Schena, L. 2015. Olive leachates affect germination of Colletotrichum godetiae conidia and the development of appressoria. Phytopathol. Mediterr. 54:35-44.

Agosteo, G. E., Scolaro, L., and Previtera, G. 2007. Non-conventional chemical control of olive anthracnose. IOBC WPRS Bull. 30:245-248.

Akhtar, S., Ismail, T., Fraternale, D., and Sestili, P. 2015. Pomegranate peel and peel extracts: Chemistry and food features. Food Chem. 174:417-425.

Cacciola, S. O., Faedda, R., Sinatra, F., Agosteo, G. E., Schena, L., Frisullo, S., and Magnano di San Lio, G. 2012. Olive anthracnose. J. Plant Pathol. 94: $29-44$.

Chattaoui, M., Raya, M. C., Bouri, M., Moral, J., Perez-Rodriguez, M., Trapero, A., Msallem, M., and Rhouma, A. 2016. Characterization of a Colletotrichum population causing anthracnose disease on olive in northern Tunisia. J. Appl. Microbiol. 120:1368-1381.

Chen, Y., and Dai, G. 2012. Antifungal activity of plant extracts against Colletotrichum lagenarium, the causal agent of anthracnose in cucumber. J. Sci. Food Agric. 92:1937-1943.

Damm, U., Cannon, P., Woudenberg, J., and Crous, P. 2012. The Colletotrichum acutatum species complex. Stud. Mycol. 73:37-113.

Faedda, R., Agosteo, G. E., Schena, L., Mosca, S., Frisullo, S., Magnano di San Lio, G., and Cacciola, S. O. 2011. Colletotrichum clavatum sp. nov. identified as the causal agent of olive anthracnose in Italy. Phytopathol. Mediterr. 50:283-302.

Glazer, I., Masaphy, S., Marciano, P., Bar-Ilan, I., Holland, D., Kerem, Z., and Amir, R. 2012. Partial identification of antifungal compounds from Punica granatum peel extracts. J. Agric. Food Chem. 60:4841-4848.

Graniti, A., Frisullo, S., Pennisi, A., and Magnano di San Lio, G. 1993. Infections of Glomerella cingulata on olive in Italy. EPPO Bull. 23:457-465.

Guidarelli, M., Carbone, F., Mourgues, F., Perrotta, G., Rosati, C., Bertolini, P., and Baraldi, E. 2011. Colletotrichum acutatum interactions with unripe and ripe strawberry fruits and differential responses at histological and transcriptional levels. Plant Pathol. 60:685-697.

Landum, M. C., do Rosário, M., Félix, J., Alho, R., Garcia, M. J., Cabrita, F. R., and Varanda, C. M. 2016. Antagonistic activity of fungi of Olea europaea L. against Colletotrichum acutatum. Microbiol. Res. 183:100-108.

Li Destri Nicosia, M. G., Pangallo, S., Raphael, G., Romeo, F. V., Strano, M. C., Rapisarda, P., Droby, S., and Schena, L. 2016. Control of postharvest fungal rots on citrus fruit and sweet cherries using a pomegranate peel extract. Postharvest Biol. Technol. 114:54-61.

Malacrinò, A., Schena, L., Campolo, O., Laudani, F., Mosca, S., Giunti, G., Strano, C. P., and Palmeri, V. 2017. A metabarcoding survey on the fungal microbiota associated to the olive fruit fly. Microb. Ecol. 73:677-684.

Malacrinò, A., Schena, L., Campolo, O., Laudani, F., and Palmeri, V. 2015. Molecular analysis of the fungal microbiome associated with the olive fruit fly Bactrocera oleae. Fungal Ecol. 18:67-74.

Moral, J., Xaviér, C., Roca, L. F., Romero, J., and Moreda, W. 2014. La Antracnosis del olivo y su efecto en la calidad del aceite. Grasas Aceites 65:e28.

Mosca, S., Nicosia, M. G. L. D., Cacciola, S. O., and Schena, L. 2014. Molecular analysis of Colletotrichum species in the carposphere and phyllosphere of olive. PLoS One 9:e114031.

Nigro, F., Schena, L., Ligorio, A., Pentimone, I., Ippolito, A., and Salerno, M. G. 2006. Control of table grape storage rots by pre-harvest applications of salts. Postharvest Biol. Technol. 42:142-149.

Palou, L., Alì, A., Fallik, E., and Romanazzi, G. 2016. GRAS, plant- and animal-derived compounds as alternatives to conventional fungicides for the control of postharvest diseases of fresh horticultural produce. Postharvest Biol. Technol. 122:41-52.

Pangallo, S., Li Destri Nicosia, M. G., Raphael, G., Levin, E., Ballistreri, G., Cacciola, S. O., Rapisarda, P., Droby, S., and Schena, L. 2017. Elicitation of resistance responses in grapefruit and lemon fruits treated with a pomegranate peel extract. Plant Pathol. 66:633-640.

Pennisi, A. M., Agosteo, G. E., and Grasso, S. 1993. Chemical control of the olive rot caused by Glomerella cingulata. EPPO Bull. 23:467-472.

Romeo, F. V., Ballistreri, G., Fabroni, S., Pangallo, S., Nicosia, M. G. L. D., Schena, L., and Rapisarda, P. 2015. Chemical characterization of different sumac and pomegranate extracts effective against Botrytis cinerea rots. Molecules 20:11941-11958.

Schena, L., Abdelfattah, A., Mosca, S., Li Destri Nicosia, M. G., Agosteo, G. E., and Cacciola, S. O. 2017. Quantitative detection of Colletotrichum godetiae and $C$. acutatum sensu stricto in the phyllosphere and carposphere of olive during four phenological phases. Eur. J. Plant Pathol. 149: 337-347.

Schena, L., Mosca, S., Cacciola, S., Faedda, R., and Sanzani, S. 2014. Species of the Colletotrichum gloeosporioides and $C$. boninense complexes associated with olive anthracnose. Plant Pathol. 63:437-446.

Schena, L., Nigro, F., and Ippolito, A. 2007. Natural antimicrobials to improve storage and shelf-life of fresh fruit, vegetables and cut flowers. Pages 259-303 in: Microbial Biotechnology in Horticulture, Vol. 2. R. C. Ray and O. P. Ward, eds. Oxford \& IBH Publishing Co., New Delhi, India.

Sergeeva, V. 2011. Anthracnose in olives: Symptoms, disease cycle and management. Pages 269-274 in: Proc. 4th Int. Conf. Olive Tree Olive Products (Olivebiotech), Crete, Greece. K. S. Chartzoulakis, ed.

Spilmont, M., Léotoing, L., Davicco, M.-J., Lebecque, P., Miot-Noirault, E., Pilet, P., Rios, L., Wittrant, Y., and Coxam, V. 2015. Pomegranate peel extract prevents bone loss in a preclinical model of osteoporosis and stimulates osteoblastic differentiation in vitro. Nutrients 7:9265-9284.

Taguri, T., Tanaka, T., and Kouno, I. 2004. Antimicrobial activity of 10 different plant polyphenols against bacteria causing food-borne disease. Biol. Pharm. Bull. 27:1965-1969.

Talhinhas, P., Goncalves, E., Sreenivasaprasad, S., and Oliveira, H. 2015. Virulence diversity of anthracnose pathogens (Colletotrichum acutatum and C. gloeosporioides species complexes) on eight olive cultivars commonly grown in Portugal. Eur. J. Plant Pathol. 142:73-83.

Talhinhas, P., Mota-Capitao, C., Martins, S., Ramos, A. P., Neves-Martin, J., Guerra-Guimaraes, L., Varzea, V., Silva, M. C., Sreenivasaprasad, S., and Oliveira, H. 2011. Epidemiology, histopathology and aetiology of olive anthracnose caused by Colletotrichum acutatum and $C$. gloeosporioides in Portugal. Plant Pathol. 60:483-495.

Weir, B., Johnston, P., and Damm, U. 2012. The Colletotrichum gloeosporioides species complex. Stud. Mycol. 73:115-80. 